\title{
Effect of alginate molecular weight and $M / G$ ratio in beads properties foreseeing the protection of probiotics
}

\author{
Philippe E. Ramos ${ }^{a}{ }^{*}$, Pedro Silva ${ }^{a}$, Marta M. Alario ${ }^{b}$, Lorenzo M. Pastrana ${ }^{\text {, }}$ \\ José A. Teixeira ${ }^{\mathrm{a}}$, Miguel A. Cerqueira ${ }^{\mathrm{c}}$, António A. Vicente ${ }^{\mathrm{a}}$ \\ ${ }^{a}$ CEB - Centre of Biological Engineering, University of Minho, Campus de Gualtar, 4710-057 Braga, Portugal \\ ${ }^{\mathrm{b}}$ School of Industrial and Telecommunication Engineers, Department Chemical Engineering and Inorganic Chemistry, Universidad de Cantabria, 39005 \\ Santander, Spain \\ ${ }^{c}$ International Iberian Nanotechnology Laboratory, Av. Mestre José Veiga s/n, 4715-330 Braga, Portugal
}

\section{A R T I C L E I N F O}

\section{Article history:}

Received 2 March 2017

Received in revised form

1 August 2017

Accepted 30 August 2017

Available online 1 December 2017

\section{Keywords:}

Bacteria

Capsules

Polysaccharide

Alginate

$\beta$-D-mannuronic acid

$\alpha$-L-guluronic acid

\begin{abstract}
A B S T R A C T
Probiotics are live microorganisms that when administered in adequate amounts confer a health benefit to the host. However, to accomplish this positive influence on Human health, probiotics should survive to the passage through the upper digestive tract in large numbers to unsure a desired beneficial effect in the host. Several encapsulation methods have been used to protect probiotics. Alginate is the most used biopolymer in the production of these systems, although its performance is totally dependent of its structure and chemical characteristics. In this work, alginates with different molecular weights and different mannuronic and guluronic acid residues ratio ( $\mathrm{M} / \mathrm{G}$ ratio) were used in the encapsulation of Lactococcus lactis spp. cremoris (LLC) aiming the protection of this probiotic bacteria against the harsh conditions of digestion. Alginate-based beads were produced using an external gelation process (extrusion technique) where variables regarding the processing conditions and alginate chemical characteristics were studied to assess their relevance in this process aiming the most efficient encapsulation system. The most important variables influencing the size of alginate beads were the alginate concentration, alginate type $(\mathrm{M} / \mathrm{G}$ ratio and molecular weight) and the nozzle diameter. Beads with sizes ranged between 1.9 and $3.0 \mathrm{~mm}$ were produced using different alginates. Fourier transform infrared (FTIR) spectroscopy showed relevant differences between beads produced proving the impact of different $\mathrm{M} / \mathrm{G}$ ratios in the beads' chemical structure. In general, low molecular weight and low $\mathrm{M} / \mathrm{G}$ ratio alginate (Protanal LFR5/60) proved to produce the most well organized (according to SEM analyses), less permeable (pore diameter of $2.52 \mathrm{~nm}$ ) and stronger alginate beads, moreover molecular weight and $\mathrm{M} / \mathrm{G}$ ratio proved to be an important variable on the protection of probiotics against the harsh conditions of digestion. Produced beads proved to be efficient in the protection of probiotics (i.e. high viability), with the best performance presented by the medium and low molecular weight alginates.
\end{abstract}

(ㄷ) 2017 Elsevier Ltd. All rights reserved.

\section{Introduction}

Nowadays, probiotics are live microorganisms that when administered in adequate amounts confer a health benefit to the host, being these recognized in several countries (Food and Agriculture Organization of the United Nations/World Health Organization, 2001). Probiotics are able to induce a positive effect on Human health, such as: the production of pathogen inhibitory

\footnotetext{
* Corresponding author

E-mail address: philippecr18@gmail.com (P.E. Ramos).
}

substances; blocking of pathogenic bacterial cells adhesion sites; nutrient competition and production; degradation of toxins and toxin receptors; and the modulation of the immune responses (Prakash, Tomaro-Duchesneau, Saha, \& Cantor, 2011). Probiotics have already presented some positive effects on human health, such as: the reduction of the expression of some biomarkers responsible for colonic cancer; treatment and prevention of acute diarrhoea in children; prevention of an initial attack of pouchitis, maintaining remission of ulcerative colitis; to alleviate symptoms in persons with functional abdominal pain; improve lactose digestion and reduce symptoms related to lactose intolerance; and to reduce the risk of necrotizing enterocolitis (Aureli et al., 2011; 
Sullivan \& Nord, 2005).

However, to accomplish this positive influence on Human health, probiotics should survive to the passage through the upper digestive tract in large numbers to ensure a desired beneficial effects in the host (Gilliland, 1989). The minimum number of viable cells suggested to achieve the benefits mentioned before is in the range of $10^{8}-10^{9}$ viable cells per day/dose (Hou, Lin, Wang, \& Tzen, 2003; Doleyres \& Lacroix, 2005). Considering the limitations of free probiotics survival during digestion, microencapsulation is generally seen as a simple and efficient solution to improve probiotics survival during this process. The most common techniques used in the encapsulation of probiotics are extrusion, emulsification and spray-drying (Kailasapathy, 2009; Tripathi \& Giri, 2014). Extrusion has been the most used technique on the microencapsulation of probiotics, due to its simplicity of operation, good performance of the process in a laboratorial environment, lower cost, and assurance of a high cell viability (de Vos, Faas, Spasojevic, \& Sikkema, 2010). An important issue in probiotics encapsulation is the size of the produced capsules, because of its influence in probiotics protection and into alterations on food eating sensation, changing the organoleptic properties of foods. The main variables that influence the capsules' size in extrusion technique are: the concentration of the polymer and cross-linker solutions; the flow-rate of the dropping solution; the distance from the needle to the crosslink solution; and the nozzle size (Brun-Graeppi et al. 2011). To create the main structure of these capsules, divalent calcium ions $\left(\mathrm{Ca}^{2+}\right)$ are commonly used, although other ions can also be applied (Tam et al., 2011). Regarding the different polymers used, alginate is the most applied material to capsules formation, due to its low price, facility to gel formation and biocompatibility (Chen, Wang, Sánchez-Soto, Schiraldi, \& a, 2012; Klein, Stock, \& Vorlop, 1983, pp. 86-91; Quong, Neufeld, Skjåk-Braek, \& Poncelet, 1998; Smidsrd \& Skjak-Brae, 1990; Tanaka \& Matsumura, 1983). Alginate is a polysaccharide extracted from brown algae and is composed of randomly 1-4 linked $\beta$-D-mannuronic acid and $\alpha$-L-guluronic acid, M blocks and G blocks, respectively (Smidsrd \& Skjak-Brae, 1990). Alginate composition changes depending of its molecular weight (MW) and the ratio between $M$ and G blocks (M/G ratio), that leads to alginates with different characteristics when crosslinked with calcium ions. More specifically, G blocks have more affinity to calcium ions than $\mathrm{M}$ blocks. These characteristics are able to influence the structure of the capsule, thus creating different capsules considering their permeability to low molecular weight compounds. In one hand, alginates with a higher $\mathrm{M} / \mathrm{G}$ ratio are capable to create more permeable alginate gel matrices (Khanna, Moya, Opara, \& Brey, 2010) and in the other hand alginates with a lower $\mathrm{M} / \mathrm{G}$ ratio lead to stronger structures due to the bigger affinity of the $\mathrm{G}$ blocks with calcium ions, compared to M blocks (Sarmento, Ribeiro, Veiga, Ferreira, \& Neufeld, 2007). As mentioned before alginate has been used in several works to protect probiotics using different alginates (Barbosa \& Teixeira, 2016; Smidsrd \& Skjak-Brae, 1990). However, in general these works do not focus in using different types of alginate. Even so, Mandal, Puniya, and Singh (2006) studied how alginate concentration could influence the survival of Lactobacillus casei NCDC-298, concluding that the survival increased proportionally with alginate's concentration. There are some works where alginates with different characteristics are used although the structures produced are not applied in probiotics protection (Bajpai \& Sharma, 2004; Klein et al., 1983, pp. 86-91). Therefore, there is a lack of information about which alginate characteristics (MW and M/G ratio) suits better the protection of probiotics considering the harsh conditions of digestion.

This work evaluates how the different variables during extrusion influenced beads' size and how alginates with different molecular weight and $\mathrm{M} / \mathrm{G}$ ratio influence the beads' size, porosity, and their capacity to protect probiotics against the harsh conditions of digestion.

\section{Methods and materials}

\subsection{Materials}

Sodium alginate Protanal CR8133 (M/G = 65/35, MW $=90-180 \mathrm{kDa})$, Protanal CR8223 $(\mathrm{M} / \mathrm{G}=65 / 35$, MW $=250-350 \mathrm{kDa})$ and Protanal LFR5/60 (M/G $=30 / 70$, $\mathrm{MW}=20-60 \mathrm{kDa}$ ) were kindly given by FMC BioPolymer (Brussels, Belgium) and presented a viscosity for a $1 \%$ solution at $20^{\circ} \mathrm{C}$ and at $30 \mathrm{rpm}$ of $39 \mathrm{mPa} \mathrm{s}, 326 \mathrm{mPa}$ s and $7 \mathrm{mPa}$, respectively, measured with a rotational viscometer (Model ELV-8, Viscometers U.K. Ltd, London, U.K.). Calcium chloride $\left(\mathrm{CaCl}_{2}\right)$ was purchased from Panreac (Barcelona, Spain). M17 broth was purchased from Oxoid (Hampshire, England). M17 agar was purchased from Merck (Munich, Germany). Potassium chloride $(\mathrm{KCl})$, monopotassium phosphate $\left(\mathrm{KH}_{2} \mathrm{PO}_{4}\right)$, sodium bicarbonate $\left(\mathrm{NaHCO}_{3}\right)$, sodium chloride $(\mathrm{NaCl})$, magnesium chloride hexahydrate $\left(\mathrm{MgCl}_{2}\left(\mathrm{H}_{2} \mathrm{O}\right)_{6}\right)$, ammonium carbonate $\left(\left(\mathrm{NH}_{4}\right)_{2} \mathrm{CO}_{3}\right)$, calcium chloride dihydrate $\left(\mathrm{CaCl}_{2}\left(\mathrm{H}_{2} \mathrm{O}\right)_{2}\right)$, sulfuric acid $\left(\mathrm{H}_{2} \mathrm{SO}_{4}\right)$, L-lactic acid $\left(\mathrm{C}_{3} \mathrm{H}_{6} \mathrm{O}_{3}\right)$, hydrogen chloride $(\mathrm{HCl})$, sodium citrate $\left(\mathrm{Na}_{3} \mathrm{C}_{6} \mathrm{H}_{5} \mathrm{O}_{7}\right)$, phosphatebuffered saline (PBS), were purchased from Sigma-Aldrich (St. Louis, USA). To perform the gastrointestinal simulations pepsin (from porcine, car $\mathrm{n}^{\circ}$ SLBL2143V, $3616 \mathrm{U}_{\mathrm{Umg}}^{-1}$ ), pancreatin (from

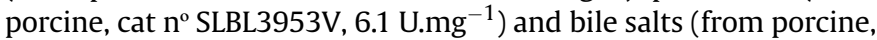
cat $\mathrm{n}^{\circ}$ SLBK9078V, $164 \mathrm{mM}$ ) were purchased from Sigma-Aldrich. The probiotic used in this work, Lactococcus lactis ssp. cremoris SK 110 (LLC), was obtained from Nizo (Nizo Food Research, Ede, The Netherlands).

\subsection{Preparation of alginate beads by external extrusion}

Alginate beads production were studied based on two experimental designs where external and internal parameters were evaluated separately (see section 2.12 Statistical analysis). Briefly, a volume of $10 \mathrm{~mL}$ of alginate solution (with the concentration tested in each experiment), was dropped in $90 \mathrm{~mL}$ of a solution of $\mathrm{CaCl}_{2}$, with different concentrations. After that the alginate solution was transferred to a syringe, and dropwise, with the help of a syringe pump, at different flow rates, through needles with different diameters, into the $\mathrm{CaCl}_{2}$ solution that was placed at variable distances, and magnetically stirred (with different stirring speeds). After the sodium alginate solution had been extruded into the $\mathrm{CaCl}_{2}$ solution, the solution continued to be magnetically stirred for $20 \mathrm{~min}$, in order to allow alginate beads to harden. Afterwards, the alginate beads were recovered by a sieve and used as it or freezedried.

In Experiment a), external variables were studied such as: flow rate $\left(1,3\right.$ and $\left.5 \mathrm{~mL} \mathrm{~min}{ }^{-1}\right)$, needle- $\mathrm{CaCl}_{2}$ solution distance $(1,5$ and $10 \mathrm{~cm})$ and the stirring speed $(60,100$ and $300 \mathrm{rpm})$. The following internal parameters were maintained: $2 \%(\mathrm{w} / \mathrm{v})$ of sodium alginate Protanal CR8133 solution, a $0.8 \mathrm{~mm}$ needle diameter and a $0.1 \mathrm{~mol} . \mathrm{L}^{-1} \mathrm{CaCl}_{2}$ solution. In Experiment b), internal variables were studied such as: needle diameter $(0.3 ; 0.6$ and $0.9 \mathrm{~mm})$, alginate Protanal CR8133 concentration (1,2 and $3 \% \mathrm{w} / \mathrm{v}$ ) and $\mathrm{CaCl}_{2}$ concentration (0.25, 0.5 and 1 mol. $\left.\mathrm{L}^{-1}\right)$. For Experiment b) and c) the following conditions were maintained: $300 \mathrm{rpm}, 1 \mathrm{~mL} \mathrm{~min}^{-1}$ and $1 \mathrm{~cm}$ of distance. To the last test, where the three different alginates were tested, the conditions used were: $0.3 \mathrm{~mm}$ needle diameter, a 1 mol. $\mathrm{L}^{-1} \mathrm{CaCl}_{2}$ concentration and a $1 \%(\mathrm{w} / \mathrm{v})$ of sodium alginate solution was used in order to guarantee the spherical shape and uniformity of the beads, being the other variables maintained as referred before. 


\subsection{Size measurement}

Diameter measurements were performed through microscopy with a $4 \times$ or $10 \times$ magnification (Olympus BX51). Pictures of the samples covered at least $40 \%$ of the beads, being Image J software for size measurement.

\subsection{Fourier transform infrared (FTIR) spectroscopy}

FTIR analyses were carried out with a Thermo Nicolet 6700 spectrometer (Thermo Scientific, Waltham, MA, USA) in the wavenumber region of $600-4000 \mathrm{~cm}^{-1}$ using 16 scans for each sample. The beads were freeze-dried prior to FTIR measurements.

\subsection{Scanning electron microscopy}

Morphological analysis was performed in an Ultra-high resolution Field Emission Gun Scanning Electron Microscopy (FEG-SEM), NOVA 200 Nano SEM, FEI Company. Secondary electron images were performed with an acceleration voltage of $10 \mathrm{kV}$. Samples were covered with a very thin film (10 nm) of Au-Pd (80-20 wt \%), using a high resolution sputter coater, 208HR Cressington Company, coupled to a MTM-20 Cressington High Resolution Thickness Controller.

\subsection{Brunauer-emmett-teller method (BET) and barret-joyner- halenda method $(\mathrm{BJH})$ analyses}

Samples were previously degassed using a vacuum line, at $25^{\circ} \mathrm{C}$ (overnight). To measure the specific surface area, pore volume and average pore diameter the BET and BJH method analyses were performed using low temperature $\mathrm{N} 2$ adsorption-desorption analysis (Autosorb iQ Station 2, Quantachrome Instruments).

\subsection{Energy-dispersive X-ray spectroscopy}

Alginate beads were characterized using a desktop scanning electron microscope (SEM) coupled with energy-dispersive X-ray spectroscopy (EDS) analysis (Phenom ProX with EDS detector (Phenom-World BV, Netherlands)). All results were acquired using the ProSuite software integrated with Phenom Element Identification software, allowed for the quantification of the concentration of the elements present in the alginate beads, expressed in either weight or atomic concentration.

The different freeze dried samples of beads were added to aluminium pin stubs with electrically conductive carbon adhesive tape (PELCO Tabs ${ }^{\mathrm{TM}}$ ), with the excess of freeze dried beads removed using compressed air. Samples were captured without coating. The aluminium pin stub was then placed inside a Phenom Standard Sample Holder, and at least 3 different areas for each sample were analysed for elemental composition. EDS analysis were conducted with an intensity point of $15 \mathrm{kV}$ (Ayarza, Coello, \& Nakamatsu, 2017; Cadena, 2016).

\subsection{Bacterial growth and preparation of cell suspensions}

The cultures of probiotic bacteria Lactococcus lactis subsp. cremoris (LLC) were cultured and propagated, overnight, in M17 broth at $30^{\circ} \mathrm{C}$ under anaerobic conditions. The bacteria were collected by centrifugation at $2000 \mathrm{~g}$ for $5 \mathrm{~min}$, and washed in PBS ( $\mathrm{pH} 7.4$ ). A mixture of bacteria suspended in PBS solution was prepared for each experiment.

\subsection{Probiotics encapsulation}

After section 2.2, the parameters and procedure for LLC encapsulation was performed by using a volume of $9 \mathrm{~mL}$ of sterile alginate solution $(1 \% \mathrm{w} / \mathrm{v})$, combined with $1 \mathrm{~mL}$ of cells + PBS, previously prepared, and $90 \mathrm{~mL}$ of a sterile $0.25 \mathrm{mol.L} \mathrm{L}^{-1}$ solution of $\mathrm{CaCl}_{2}$. The

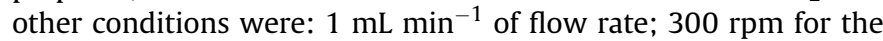
stirring speed; $1 \mathrm{~cm}$ for the needle- $\mathrm{CaCl}_{2}$ solution distance; $0.4 \mathrm{~mm}$ of needle diameter; and a stirring/hardening time of $20 \mathrm{~min}$.

\subsection{Bacterial viability quantification}

The bacterial viability was determined through the viable counts of the entrapped bacteria in the beads. For that the produced beads were re-suspended and stirred in $50 \mathrm{~mL}$ of sodium citrate $(0.1 \% \mathrm{w} / \mathrm{v})$ during $10 \mathrm{~min}$, in order to achieve their total destruction, after which the sample was retrieved, diluted and plated in M17 agar. The quantification of the number of entrapped cells was determined through plate count using M17 agar (incubated in aerobic conditions at $30^{\circ} \mathrm{C}$, during $24 \mathrm{~h}$ ).

\subsection{Harmonized in vitro digestion}

The in vitro digestion was conducted using a gastrointestinal simulation test based on the protocol presented by Minekus et al. (2014) with some modifications. The solutions used were Simulated Salivary Fluid (SSF), Simulated Gastric Fluid (SGF) and Simulated Intestinal Fluid (SIF). These solutions were warmed-up at $37^{\circ} \mathrm{C}$ before the beginning of the experiment.

The first step was the introduction of a $5 \mathrm{~g}$ sample ( $5 \mathrm{~g}$ of wet beads) in a $50 \mathrm{~mL}$ Falcon with $4 \mathrm{~mL}$ of SSF. This mixture was incubated for $2 \mathrm{~min}$ at $37^{\circ} \mathrm{C}$ (all the incubation steps are performed at this temperature and shaking conditions). The next step was to add $8 \mathrm{~mL}$ of SGF and a volume of porcine pepsin in water (an exact volume to achieve a $2000 \mathrm{U}_{\mathrm{mL}}^{-1}$ in the final mixture), adjusting the $\mathrm{pH}$ to 3 (using an $\mathrm{HCl} 1 \mathrm{~mol} . \mathrm{L}^{-1}$ solution). The mixture was incubated during $2 \mathrm{~h}$. After this, an exact volume of pancreatin suspension to achieve a $200 \mathrm{U} \cdot \mathrm{mL}^{-1}$ in the final mixture, an exact volume of bile solution to achieve a final concentration of $10 \mathrm{mmol} . \mathrm{L}^{-1}$ and $8 \mathrm{~mL}$ of SIF were added. Falcons were incubated during $2 \mathrm{~h}$ and sampling was performed each 30 min during the gastric and intestinal simulation. All the experiments were performed in triplicate.

\subsection{Statistical analysis}

The statistical technique Experimental Design (Industrial DOE) was used for the study of variables affecting the beads size with a two-level factorial design with a central point (11 runs). The standardized effects were carried out using Pareto's charts, considering $p<0.05$ statistically significant. The software Statistica 7.0 (Statsoft, Inc., Tulsa, OK, USA) was used for all statistical analysis.

\section{Results/discussion}

\subsection{Beads production by external gelation}

The beads' size produced by the extrusion technique depends on several variables. To understand which variables influenced the size of beads, different conditions were tested. The range used for these variables was selected from previously published studies (Albertini et al., 2010; Krasaekoopt, Bhandari, \& Deeth, 2004).

\subsubsection{Influence of external variables - experiment a)}

In the first set of experiments, the external variables (flow rate, 
needle- $\mathrm{CaCl}_{2}$ solution distance and the stirring speed) of the system were studied in order to understand how they affect the formation of alginate beads. The standardized effect estimate (absolute value) showed that the variables: needle- $\mathrm{CaCl}_{2}$ solution distance (3.79) and flow rate (3.15) influenced positively the size of the beads; but the variable stirring rate did not $(-0.184)(p=0.05$; MS Residual 0.0358). Fig. 1a shows the influence of different variables in the size of alginate beads (the stirring rate was not include once it does not present a presents significant statistically effect on the size of the beads). The smaller beads were formed with lower flow rates and smaller needle- $\mathrm{CaCl}_{2}$ solution distance, leading to the formation of beads with a size of $2.670 \pm 0.186 \mathrm{~mm}$. Higher flow rates produced bigger beads, that is explained by the flow rate and the rate at which the droplets fall down (Klokk \& Melvik, 2002). A higher flow rate leads to bigger drops before they are drop-off, although this fact depends on the polymer viscosity. At lower viscosities this fact might not be noticed although with a $1 \%(\mathrm{w} / \mathrm{v})$ of alginate the viscosity is high enough to create these differences. Higher needle- $\mathrm{CaCl}_{2}$ distances will influence the diving of the drop into the calcium solution and thus will highly influence the alginate drop structure. This factor will lead to a less organized bead, allowing a bigger penetration of calcium ions and consequently beads with higher sizes (Kobašlija \& McQuade, 2006).

\subsubsection{Influence of internal variables - experiment $b$ )}

Once the effect of external variables on the beads size was determined, internal variables were studied (needle diameter, alginate concentration and $\mathrm{CaCl}_{2}$ concentration), being the results presented in Fig. 1 b. The standardized effect estimate (absolute value) showed that the variables: needle diameter (26.52) and alginate concentration (2.73) were influencing positively the size of alginate beads. At the same time, results showed that the $\mathrm{CaCl}_{2}$ concentration variable does not affect the size of the beads $(0.28)$. The $\mathrm{CaCl}_{2}$ concentration might not significantly influence the size of the beads due to an excess of $\mathrm{CaCl}_{2}$ mass used ( $p=0.05$; MS Residual 0.0337). Therefore, the $\mathrm{CaCl}_{2}$ concentration variable was not considered in Fig. 1b. The needle diameter variable was the most influencing variable on the size of the beads, being the smallest beads obtained with a needle diameter of $0.3 \mathrm{~mm}(1 \%$ (w) v) alginate solution, 1 mol. $\mathrm{L}^{-1}$ of $\mathrm{CaCl}_{2}$ ), with a size of $1.940 \pm 0.094 \mathrm{~mm}$. These results were expected considering that the size of the drops created, that corresponds approximately to the beads' final size, are influenced directly by the needle diameter (Thu, Bruheim, Espevik, \& Skj, 1996; Thu, Bruheim, Espevik, Smidsrød, 1996). Higher alginate concentrations will also create bigger beads, due to the higher viscosity of the polymer solution that will originate bigger drops (Thu, Bruheim, Espevik, \& Skj, 1996; Thu, Bruheim, Espevik, Smidsrød, 1996; Zhang, Zhang, \& McClements, 2016).

\subsubsection{Influence of the alginate type}

To understand how different alginates would influence beads size, the alginate LFR5/60, CR8223 and CR8133 were used for beads production using the same conditions. The results showed that the average diameter of the beads produced were: for alginate LFR5/ $60-2.26 \pm 0.11 \mathrm{~mm}$, alginate CR8223-2.00 $\pm 0.02 \mathrm{~mm}$ and alginate CR8133-1.99 $\pm 0.02 \mathrm{~mm}$. According to these results is clear that a high $\mathrm{G}$ content alginate, even with a low molecular weight, is able to create larger beads in comparison with low $\mathrm{G}$ content alginates. In general, bigger molecules will create bigger beads. The lower size molecules (low molecular weight) of alginate allow an easy construction and fitting of a higher mass of molecules, thus creating beads with smaller sizes. However, it is important to mention that in this case the higher and medium molecular weight alginates had a low $\mathrm{G}$ content and the smaller molecular weight alginate had a high $\mathrm{G}$ content, which might justify these results. High G content alginates, in a media with an excess of calcium ions, are able to create more interactions between molecules and because of that create bigger and stronger net gels (Klokk \& Melvik, 2002). These characteristics will allow a higher swelling and because of that a bigger bead's diameters which justify that a low molecular weight alginate is able to create bigger beads. Another fact is that beads produced using alginate CR8223 and CR8133 presented the same diameter, although they have different molecular weight and viscosity values, although they present the same $\mathrm{M} / \mathrm{G}$ ratio. This fact implies that there is a strong relation between beads size and $\mathrm{M} / \mathrm{G}$
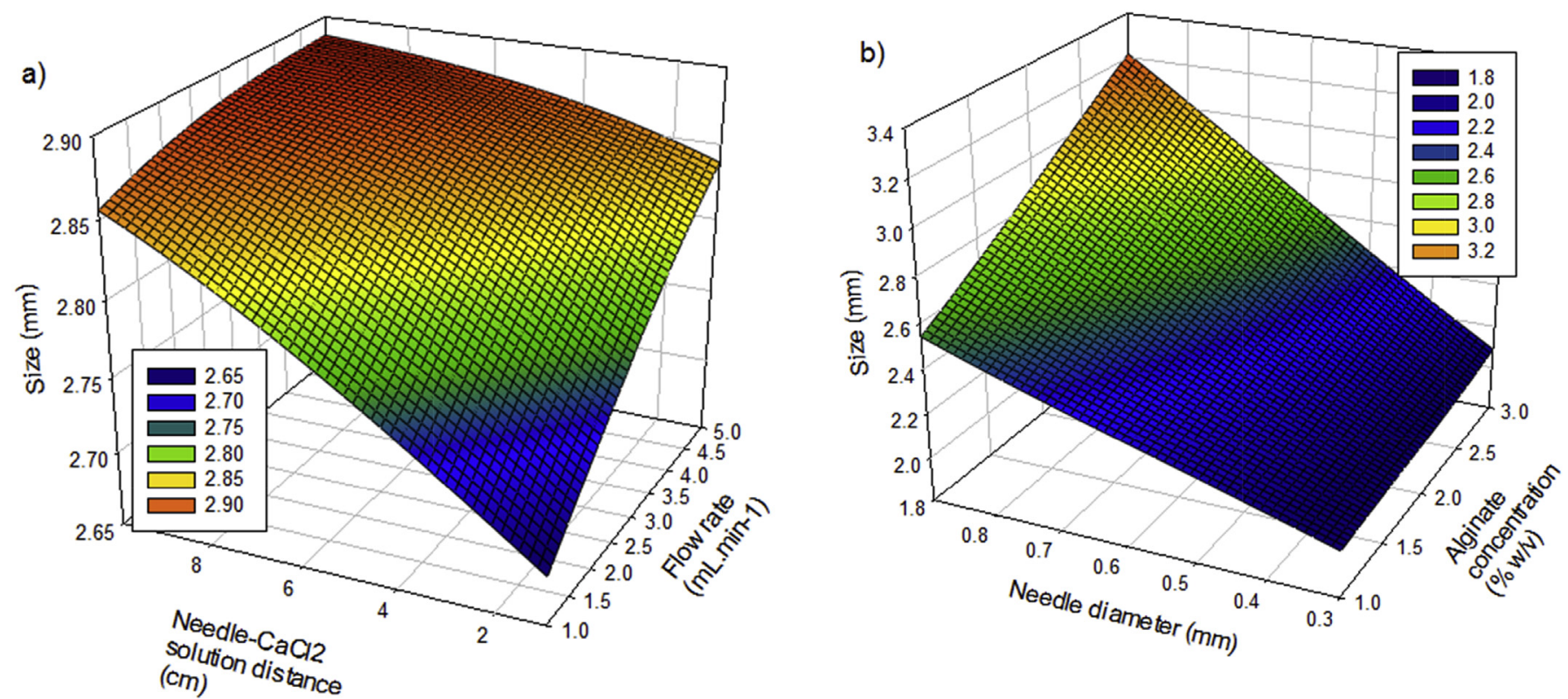

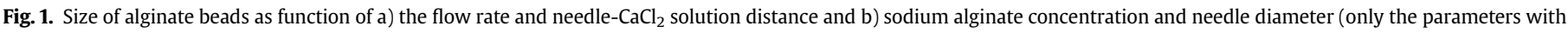
statistical influence were considered to create this figures). 
ratio.

Nevertheless, to a full understanding of the influence of the molecular weight and $M / G$ ratio on the beads properties, other alginate's types should be used to study the influence of each variable in the beads' size.

\subsection{Alginate and alginate beads FTIR analyses}

Fig. 2 presents the FTIR spectra of the different samples of alginate powder and alginate beads. It is possible to identify at $1590 \mathrm{~cm}^{-1}$ and $1400 \mathrm{~cm}^{-1}$ the stretching vibrations of the $\mathrm{COO}^{-}$ group, characteristic of an alginate structure (Fig. 2a) (Shi, Alves, \& Mano, 2007; Tam et al., 2005). The differences in M/G ratio of alginate are identified in FTIR analyses where generally mannuronic acid units have a band at approximately $815 \mathrm{~cm}^{-1}$ (Fertah, Belfkira, \& Dahmane, 2014). This pick can be identified in Fig. 2b in both powder samples (CR8223 and CR 8133). In the other hand, in Fig. 2c it is possible to identify that no peak at $815 \mathrm{~cm}^{-1}$ appears but is possible to identify another peak at $808 \mathrm{~cm}^{-1}$. This fact is related to the low amount of $M$ residues in the LFR5/60 alginate, since is the one with highest $\mathrm{G}$ content. There are other picks that can suggest a higher presence of $G$ residues, such as the peaks at $1320 \mathrm{~cm}^{-1}$ and $1130 \mathrm{~cm}^{-1}$ (Fig. 2d and e) (Sartori, Finch, Ralph, \& Gilding, 1997). The samples representing the alginate beads have similar results comparing with the powder results, although some differences can be identified. The peak at $3340 \mathrm{~cm}^{-1}$ (representing $\mathrm{O}-\mathrm{H}$ stretching), Fig. 2f, increased its intensity in all beads samples comparing with the powder samples, that can be justified by the presence of water. Other important difference between beads and powder samples are the peak at $\sim 1610 \mathrm{~cm}^{-1}$ (Fig. $2 \mathrm{~g}$ ) that also presents an higher intensity in beads samples, due to the substitution of sodium ions for calcium ions resulting on a change of the charge density of carboxyl groups (Sartori et al., 1997). Another interesting fact about this intensity increase, in $~ 1610 \mathrm{~cm}^{-1}$ peak, is that comparing the beads spectra is clear that the alginate LFR5/60 had a higher increase than the beads produced using other types of alginate. These results can be justified by the biggest amount of $G$ residues in this sample creating because of this samples with an higher content of calcium and so a bigger impact in these peaks.

\subsection{Energy-dispersive X-ray spectroscopy (EDS)}

Sodium alginates is the sodium salt of alginic acid that is chemically constituted by carbon, hydrogen, sodium and oxygen elements $\left(\mathrm{C}_{6} \mathrm{H}_{9} \mathrm{NaO}_{7}\right)$ (Thu, Bruheim, Espevik, \& Skj, 1996; Thu, Bruheim, Espevik, Smidsrød, 1996). Alginate is constituted by glucuronic acid and mannuronic acid both with the same chemical constitution of $\mathrm{C}_{6} \mathrm{H}_{10} \mathrm{O}_{7}$ but with different structural conformations (Draget, Stokke, Yuguchi, Urakawa, \& Kajiwara, 2000). EDS analysis showed that alginate beads were mainly constituted by oxygen, calcium, chlorine and carbon, existing also a small percentage of sodium. The constitution of the beads produced with different alginates is presented in Table 1.

Table 1 shows that beads produced by alginates CR8133 and CR 8223 are very similar considering their chemical composition, being the most relevant difference the presence of sodium in the CR8223 beads. These results were expected considering that these alginates had the same $M / G$ ratio (65/35) which created, per mass of alginate beads, similar composition of the presented elements.

The most relevant differences are in the results of alginate beads prepared with LFR 5/60 in comparison with the other experiments. According to Table 1, LFR5/60 sample had the lower concentrations of oxygen and carbon, but at the same time showed higher concentrations of chlorine and calcium. The lower molecular weight of LFR 5/60 alginate allows the creation of larger beads, as discussed before in sections 3.1 .3 and in 3.3, leading to beads with a higher entrapment capacity of calcium chloride solution. This fact results in higher concentrations of chlorine and calcium in the freeze dried beads, as shown in Table 1 . The highest concentration of calcium was obtained for the LFR 5/60 beads in the FTIR analysis (section

Table 1

Constitution of the alginate beads obtained from the different types of alginate.

\begin{tabular}{|c|c|c|c|}
\hline Samples & CR8133 beads & CR8223 beads & LFR5/60 beads \\
\hline Element & (Weight \%) & (Weight \%) & (Weight \%) \\
\hline Oxygen & $45.923 \pm 1.548$ & $44.750 \pm 6.276$ & $36.213 \pm 5.088$ \\
\hline Carbon & $27.373 \pm 0.318$ & $25.700 \pm 4.235$ & $16.207 \pm 3.478$ \\
\hline Chlorine & $15.830 \pm 1.419$ & $16.380 \pm 2.868$ & $28.870 \pm 7.069$ \\
\hline Calcium & $10.873 \pm 0.688$ & $12.183 \pm 4.150$ & $18.100 \pm 1.395$ \\
\hline Sodium & - & $0.987 \pm 1.709$ & $0.613 \pm 0.172$ \\
\hline
\end{tabular}

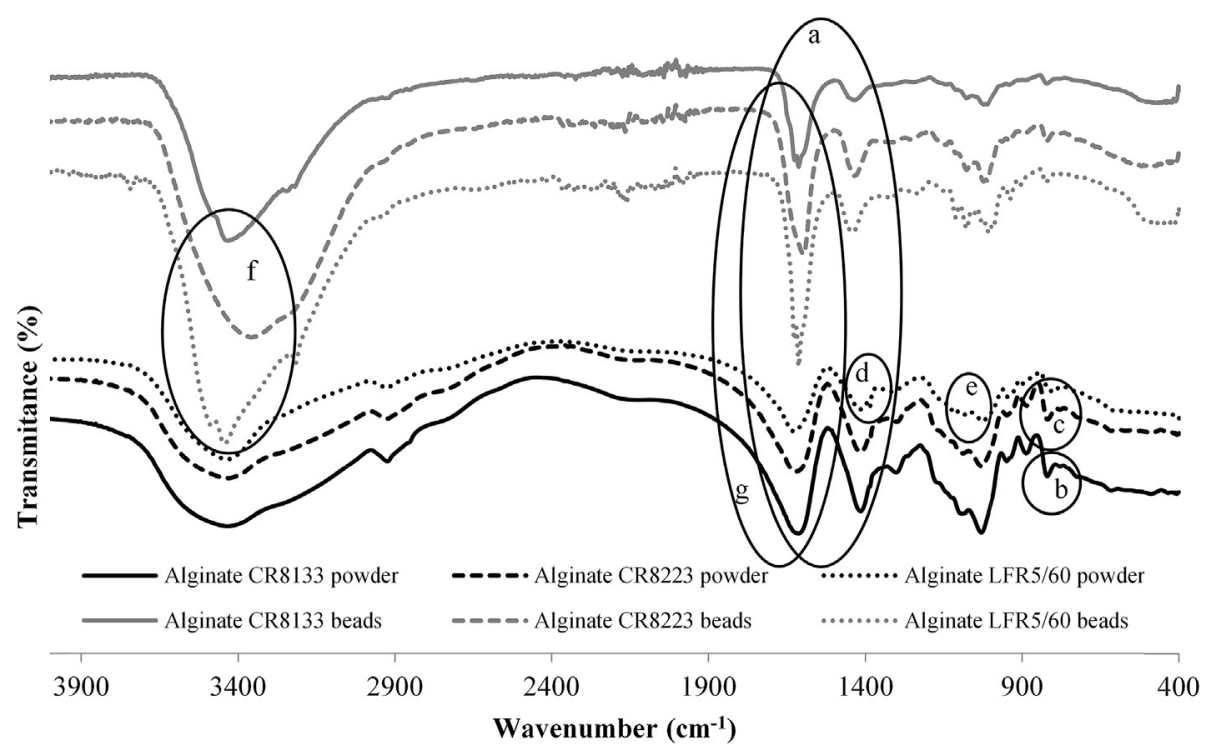

Fig. 2. FTIR spectra of the alginate samples in the form of powder and in the form of beads. 
3.2). The low concentration of sodium and higher concentration of calcium and chlorine obtained are justified by the sodium ions $\left(\mathrm{Na}^{+}\right)$substitution for calcium ions $\left(\mathrm{Ca}^{2+}\right)$, that occurs upon gelation of the alginate beads (Santos, Wei, Cho, \& Kriven, 2013).

As mentioned before the alginate solution was extruded dropwise to a calcium chloride in excess, which leads to a higher quantity of calcium chloride solution inside the alginate beads, resulting in a higher concentration of chlorine (Table 1 ).

\subsection{Beads morphology}

Fig. 3 shows the different beads produced by extrusion with alginate CR 8113, CR 8223 and LFR5/60. The alginate beads presented spherical or spheroidal morphology, although they had shrunken, producing irregular structures after freeze drying. This fact was already mentioned in other works where it was mentioned that low concentrations of alginate (lower than 5\%) would create spherical beads that when dried could shrink (Kusuktham, Prasertgul, \& Srinun, 2014). Low concentrations of alginate created a low concentration of carboxyl groups on the surface of the bead that during a drying process leads to a partial collapse of the structure, leading to the shrinkage of the beads' surface (Kusuktham et al., 2014). In Fig. 3 (A, D and G) it is possible to observe that the particles shrunken after the freeze drying process, changing from their normal shape to the presented form. The beads present a relatively smooth surface, analysing the results from a closer perspective in Fig. 3B, E and 3H. However, some differences can be identified from a cross section representation, in Fig. 3C, F and 3I. Alginate LFR5/60 (Fig. 3I) presents a more compact structure, creating less and smaller porous, comparing with the other alginate beads. These results can be justified by the low molecular weight of alginate LFR5/60 and also by its high content of G residues. The low molecular weight allows a better organization of the beads structure, creating a less porous bead. Alginate hydrogels are created due to its capacity to connect with $\mathrm{Ca}^{2+}$, by the formation of ionic bridges between $\mathrm{G}$ blocks and calcium ions (Smidsrd \& SkjakBrae, 1990). Alginate and $\mathrm{CaCl}_{2}$ are able to create strong structures, due to the consecutive position of $\mathrm{G}$ blocks on alginate that will create cavities to calcium ions to connect, being each ion able to connect to 4 different $G$ residues. This model describes the

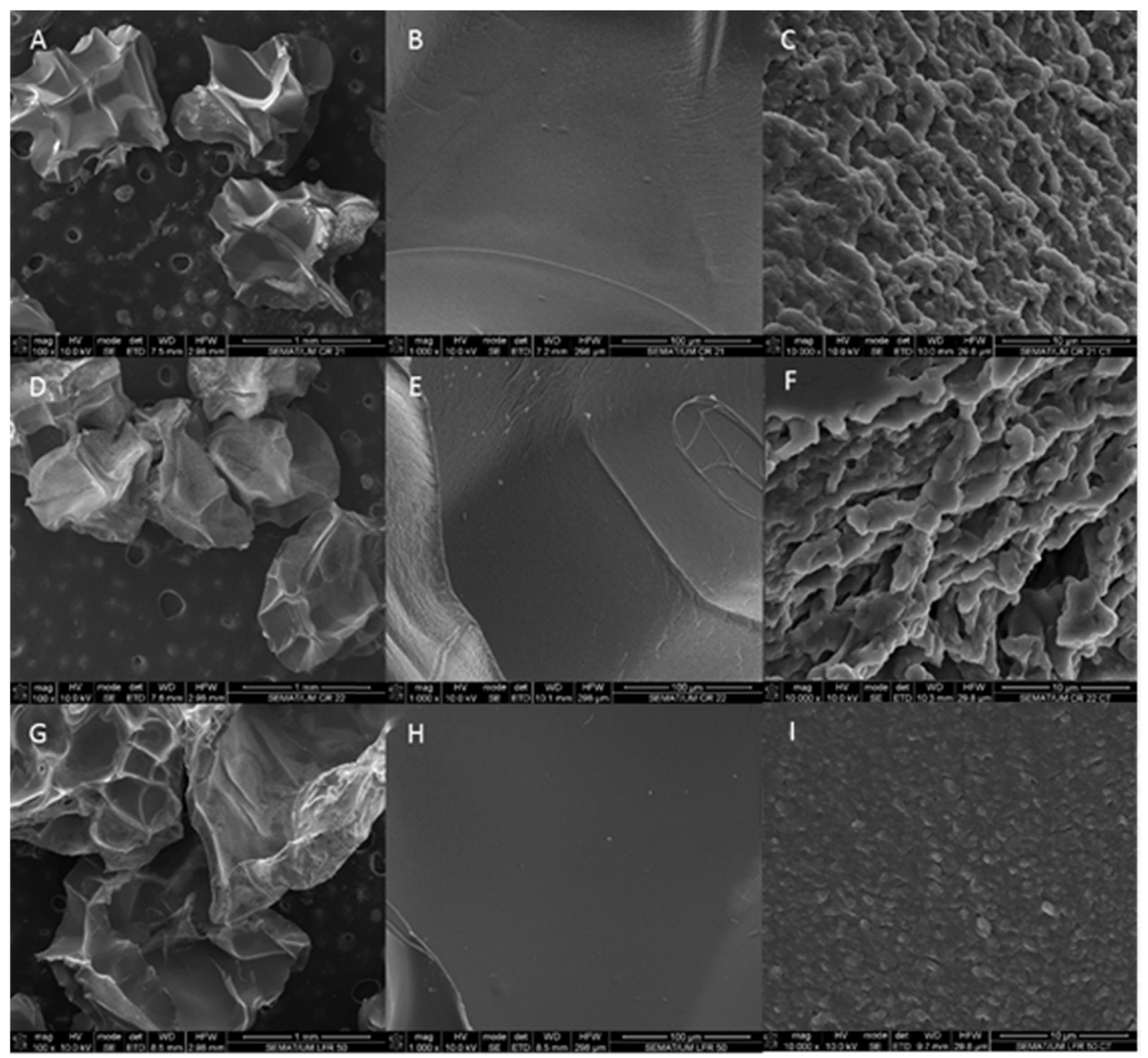

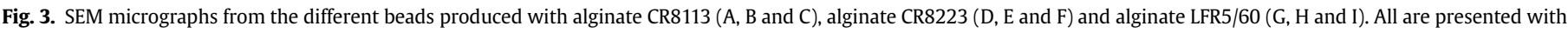
an entire bead (A, D and G), a surface analysis $(B, E$ and $H)$ and a cross section representation (C, F and I). 
Table 2

Surface area, pore volume and pore diameter of beads.

\begin{tabular}{llll}
\hline Alginate & $\begin{array}{l}\text { Surface area } \\
\left(\mathrm{m}^{2} / \mathrm{g}\right)\end{array}$ & $\begin{array}{l}\text { Pore volume } \\
\left(\mathrm{m}^{3} / \mathrm{g}\right)\end{array}$ & $\begin{array}{l}\text { Pore diameter } \\
(\mathrm{nm})\end{array}$ \\
\hline CR 8113 & 21.8 & 0.055 & 3.94 \\
CR 8223 & 36.1 & 0.068 & 3.94 \\
LFR5/60 & 13.7 & 0.034 & 2.52 \\
\hline
\end{tabular}

ionotropic gelation of alginate and is known as the "egg box" model (Draget et al., 2000; Thu, Bruheim, Espevik, \& Skj, 1996; Thu, Bruheim, Espevik, Smidsrød, 1996). Therefore, alginate LFR5/60 has characteristics that allow the creation of more connections of alginate with calcium, originating a less porous structure.

\subsection{Surface area, pore volume and pore diameter analyses}

The results about the area, volume and pore diameter of the different alginate beads, presented in Table 2, show relevant differences. It is important to notice that the beads produced by the alginates with medium and high molecular weight (CR8113 and CR8223, respectively) produced the biggest surface areas, volumes and pore diameters. In the other hand, the alginate with the lowest molecular weight and with a high G content (LFR5/60) produced the beads with smaller surface area, volume and pore diameter. As discussed before these results are justified by the more organized structure produced by the latest, with more connection points between alginate and calcium ions. The results presented in Table 2 are in accordance with other works that refer a surface area of $10-350 \mathrm{~m}^{2} / \mathrm{g}$ for alginate beads (Mihara et al., 2016), a pore volume of $0.02 \mathrm{~cm}^{3} / \mathrm{g}$ and a pore diameter around $2.5-15 \mathrm{~nm}$ (Singh \& Preeti, 2015).

\subsection{Viability of free and encapsulated LLC bacteria}

To understand how alginate beads would behave considering LLC protection during digestion, a gastrointestinal simulation was performed. Initially their capacity to retain the LLC bacteria without releasing them was assessed. The results showed that there was no release of the bacteria in the stomach simulated phase. Therefore, in the subsequent experiment, the bacterial release from the capsules was not taken into account (an initial bacteria concentration of $8 \log$ CFU was encapsulated to perform these tests). Fig. 4 shows the viability of bacteria under gastrointestinal simulation. It is clear that free LLC bacteria is not be able to survive to the tested conditions and that during the first hour of stomach's simulation all free bacteria lost their viability. These facts are in accordance with other works where in a short period of time happens a total death of the free probiotics (Cook, Tzortzis, Charalampopoulos, \& Khutoryanskiy, 2011; García-Ceja, Mani-López, Palou, \& LópezMalo, 2015; Gbassi, Vandamme, Ennahar, \& Marchioni, 2009; Iyer, Phillips, \& Kailasapathy, 2005; Krasaekoopt et al., 2004; Lee, Cha, \& Park, 2004; Sohail, Turner, Coombes, Bostrom, \& Bhandari, 2011). When encapsulation was used for probiotic protection it was evident a significant increase of the encapsulated bacteria viability, when compared with free bacteria. Equally, other works proved the efficiency of alginate beads produced by extrusion for probiotic protection (Albertini et al., 2010; Amine et al., 2014; Chandramouli, Kailasapathy, Peiris, \& Jones, 2004; Corbo, Bevilacqua, Gallo, Speranza, \& Sinigaglia, 2013; Krasaekoopt et al., 2004; Lee \& Heo, 2000; Liserre, Ré, \& Franco, 2007; Martoni et al., 2007; Muthukumarasamy, Allan-wojtas, \& Holley, 2006).

Fig. 4 shows a constant decrease on LLC viability during time, in all tested systems. The beads produced with alginate CR8133 and LFR5/60 showed to be the best protection of the LCC bacteria, being the values of cell viability with beads produced with these two alginates statistically equivalent $(p<0.05)$. For the beads produced with alginate CR8223 a substantial loss of LLC viability is observed during the experiment, up to $120 \mathrm{~min}$ (end of stomach simulation). This difference might be related to the high molecular weight of this type of alginate (250-350 kDa comparing with LFR5/60 20-60 kDa and CR8133 - 90-180 kDa) that benefited the formation of a less organized and more porous structure, as it is possible to see in Table 2 and Fig. 4. The molecular weight influences the porosity of the microcapsules created, being responsible for a higher permeability that leads to a higher contact of LLC with the outside medium. This phenomenon will be responsible for the decrease of LLC viability in that experiment, once it facilitates the diffusion of the simulated stomach phase into the beads and therefore the contact of probiotics with harsh conditions.

During beads preparation, polymers with a low molecular weight generally originate more organized structures which are therefore stronger and less porous (Drury, Dennis, \& Mooney, 2004; Leung, Nielsen, Trau, \& Timmins, 2010). Alginates CR8133 and

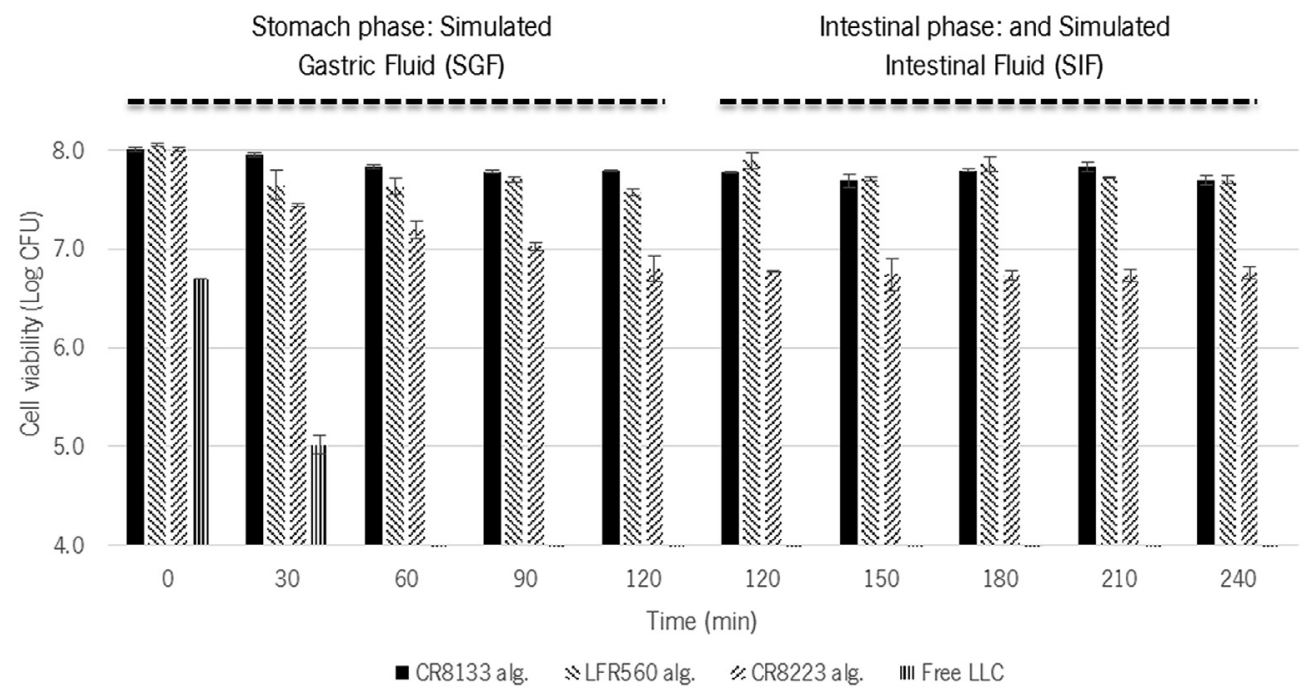

Fig. 4. Viability of free and microencapsulated LLC under a gastrointestinal simulation. 
LFR5/60, which have relatively low molecular weights, showed no relevant differences on their performance for LLC viability protection. However, some differences were expected considering the difference between these two forms regarding their molecular weight and their $M / G$ ratio. It would be expected that LFR5/60 presented the best protection of LLC viability because of its lower pore diameter $(2.52 \mathrm{~nm})$ in comparison with alginate CR8133 $(3.94 \mathrm{~nm})$. Apparently this was not sufficient to reveal a statistically different behaviour concerning LLC viability.

However, other facts might influence these results such as local buffering created by the beads. This phenomenon leads to the increase of $\mathrm{pH}$ inside the bead which originates a reduction of the negative impact of the medium in LLC viability (Cook et al., 2013). This fact might justify that beads with different porosities, produced with different alginates (CR8133 and LFR5/60), are able to present the same level of LLC protection to the harsh conditions of digestion. Another important factor that might be discussed is beads' size and its influence in LLC protection, considering that generally bigger beads are able to perform a better protection of probiotics. Although, comparing the beads produced with alginate CR8133 and LFR5/60, with average diameter of $1.99 \pm 0.02 \mathrm{~mm}$ and $2.26 \pm 0.11 \mathrm{~mm}$, respectively, results proved that in this case the beads' size did not influenced the protection of LLC, considering that the biggest bead did not presented the best protection.

\section{Conclusions}

The variables that most influenced the beads' size in the extrusion technique were the alginate concentration, alginate type (molecular weight and M/G ratio) and the nozzle diameter. These variables are directly correlated with the size of the produced beads. Alginate's characteristics such as the molecular weight and $\mathrm{M} / \mathrm{G}$ ratio, demonstrated to have a positive impact in order to accomplish a system able to protect probiotics from the harsh conditions of digestion. It is important to refer that strong differences were achieved in the protection of probiotics in tests where the only difference was the molecular weight and/or $\mathrm{M} / \mathrm{G}$ ratio of the alginates used. Therefore, alginate LFR5/60, a low molecular weight and high $\mathrm{G}$ content alginate, showed to produce the biggest, strongest and best suitable beads for probiotics protection in a digestive system.

\section{Acknowledgments}

The author Philippe E. Ramos would like to thank the Post-doc fellowship to the national agency Fundação para a Ciência e a Tecnologia (UID/BIO/04469) and to the European Regional Development Fund (FEDER) through COMPETE 2020 - Programa Operacional Competitividade e Internacionalização (POCI-01-0145FEDER-006684). The authors thank the FCT Strategic Project PEstOE/EQB/LA0023/2013 and the project "BioInd-Biotechnology and Bioengineering for Improved Industrial and Agro-Food Processes", ref. NORTE-07-0124-FEDER-000028 cofunded by the Programa Operacional Regional do Norte (ON.2-O Novo Norte), QREN, FEDER. The authors would like to acknowledge to Carlo Resini and Yury Kolen'ko from the International Iberian Nanotechnology Laboratory for the assistance in surface area, pore volume and pore diameter analyses and to Estefanía López Silva, from CACTI, University of Vigo for assistance in the FTIR analysis.

\section{References}

Albertini, B., Vitali, B., Passerini, N., Cruciani, F., Di Sabatino, M., Rodriguez, L., et al. (2010). Development of microparticulate systems for intestinal delivery of Lactobacillus acidophilus and Bifidobacterium lactis. European Journal of
Pharmaceutical Sciences: Official Journal of the European Federation for Pharmaceutical Sciences, 40(4), 359-366. http://doi.org/10.1016/j.ejps.2010.04.011.

Amine, K. M., Champagne, C. P., Raymond, Y., St-Gelais, D., Britten, M., Fustier, P., ... Lacroix, M. (2014). Survival of microencapsulated Bifidobacterium longum in Cheddar cheese during production and storage. Food Control, 37, 193-199. http://doi.org/10.1016/j.foodcont.2013.09.030.

Aureli, P., Capurso, L., Castellazzi, A. M., Clerici, M., Giovannini, M., Morelli, L., ... Zuccotti, G. V. (2011). Probiotics and health: An evidence-based review. Pharmacological Research: The Official Journal of the Italian Pharmacological Society, 63(5), 366-376. http://doi.org/10.1016/j.phrs.2011.02.006.

Ayarza, J., Coello, Y., \& Nakamatsu, J. (2017). SEM-EDS study of ionically crosslinked alginate and alginic acid bead formation. International Journal of Polymer Analysis and Characterization, 22(1), 1-10. http://doi.org/10.1080/ 1023666X.2016.1219834.

Bajpai, S. K., \& Sharma, S. (2004). Investigation of swelling/degradation behaviour of alginate beads crosslinked with $\mathrm{Ca} 2+$ and $\mathrm{Ba} 2+$ ions. Reactive and Functional Polymers, 59(2), 129-140. http://doi.org/10.1016/j.reactfunctpolym.2004.01.002.

Barbosa, J., \& Teixeira, P. (2016). Development of probiotic fruit juice powders by spray-drying: A review. Food Reviews International, 9129(April), 1-24. http:// doi.org/10.1080/87559129.2016.1175016.

Cadena, E. (2016). Microscopical and elemental FESEM and Phenom ProX-SEM-EDS analysis of osteocyte- and blood vessel-like microstructures obtained from fossil vertebrates of the Eocene Messel Pit, Germany. PeerJ, 4, e1618. http://doi. org/10.7717/peerj.1618.

Chandramouli, V., Kailasapathy, K., Peiris, P., \& Jones, M. (2004). An improved method of microencapsulation and its evaluation to protect Lactobacillus spp. in simulated gastric conditions. Journal of Microbiological Methods, 56(1), 27-35. http://doi.org/10.1016/j.mimet.2003.09.002.

Chen, H. B., Wang, Y. Z., Sánchez-Soto, M., \& Schiraldi, D. a (2012). Low flammability, foam-like materials based on ammonium alginate and sodium montmorillonite clay. Polymer (United Kingdom), 53(25), 5825-5831. http://doi.org/10.1016/j. polymer.2012.10.029.

Cook, M. T., Saratoon, T., Tzortzis, G., Edwards, A., Charalampopoulos, D., \& Khutoryanskiy, V. V. (2013). CLSM method for the dynamic observation of $\mathrm{pH}$ change within polymer matrices for oral delivery. Biomacromolecules, 1. http:// doi.org/10.1021/bm301569r.

Cook, M. T., Tzortzis, G., Charalampopoulos, D., \& Khutoryanskiy, V. V. (2011). Production and evaluation of dry alginate-chitosan microcapsules as an enteric delivery vehicle for probiotic bacteria. Biomacromolecules, 12(7), 2834-2840. http://doi.org/10.1021/bm200576h.

Corbo, M. R. Bevilacqua, A., Gallo, M. Speranza, B. \& Sinigaglia, M. (2013). Immobilization and microencapsulation of Lactobacillus plantarum: Performances and in vivo applications. Innovative Food Science and Emerging Technologies, 18, 196-201. http://doi.org/10.1016/j.ifset.2012.12.004.

de Vos, P., Faas, M. M., Spasojevic, M., \& Sikkema, J. (2010). Encapsulation for preservation of functionality and targeted delivery of bioactive food components. International Dairy Journal, 20(4), 292-302. http://doi.org/10.1016/j. idairyj.2009.11.008.

Doleyres, Y., \& Lacroix, C. (2005). Technologies with free and immobilised cells for probiotic bifidobacteria production and protection. International Dairy Journal, 15(10), 973-988. http://doi.org/10.1016/j.idairyj.2004.11.014.

Draget, K. I., Stokke, B. T., Yuguchi, Y., Urakawa, H., \& Kajiwara, K. (2000). Smallangle X-ray scattering and rheological characterization of alginate gels. 3. Alginic acid gels. Biomacromolecules, 4(6), 1661-1668. http://doi.org/10.1021/ bm034105g.

Drury, J. L., Dennis, R. G., \& Mooney, D. J. (2004). The tensile properties of alginate hydrogels. Biomaterials, 25(16), 3187-3199. http://doi.org/10.1016/j. biomaterials.2003.10.002.

Fertah, M., Belfkira, A., Dahmane, Montassir, E., Taourirte, M., \& Brouillette, F. (2014). Extraction and characterization of sodium alginate from Moroccan Laminaria digitata brown seaweed. Arabian Journal of Chemistry. http://doi.org/10.1016/j. arabjc.2014.05.003.

Food and Agriculture Organization of the United Nations/World Health Organization. (2001). Health and nutritional properties of probiotics in food including powder milk with live lactic acid bacteria (pp. 1-34). Food and Agriculture Organization of the United Nations World, (October).

García-Ceja, A., Mani-López, E., Palou, E., \& López-Malo, A. (2015). Viability during refrigerated storage in selected food products and during simulated gastrointestinal conditions of individual and combined lactobacilli encapsulated in alginate or alginate-chitosan. LWT - Food Science and Technology, 63(1), 482-489. http://doi.org/10.1016/j.lwt.2015.03.071.

Gbassi, G. K., Vandamme, T., Ennahar, S., \& Marchioni, E. (2009). Microencapsulation of Lactobacillus plantarum spp in an alginate matrix coated with whey proteins. International Journal of Food Microbiology, 129(1), 103-105. http://doi.org/10. 1016/j.ijfoodmicro.2008.11.012.

Gilliland, S. E. (1989). Acidophilus milk products: A review of potential benefits to consumers. Journal of Dairy Science, 72(5524), 2483-2494. http://doi.org/10. 3168/jds.S0022-0302(89)79389-9.

Hou, R. C. W., Lin, M. Y., Wang, M. M. C., \& Tzen, J. T. C. (2003). Increase of viability of entrapped cells of Lactobacillus delbrueckii ssp. bulgaricus in artificial sesame oil emulsions. Journal of Dairy Science, 86(2), 424-428. http://doi.org/10.3168/jds. S0022-0302(03)73620-0.

Iyer, C., Phillips, M., \& Kailasapathy, K. (2005). Release studies of Lactobacillus casei strain Shirota from chitosan-coated alginate-starch microcapsules in ex vivo porcine gastrointestinal contents. Letters in Applied Microbiology, 41(6), 
493-497. http://doi.org/10.1111/j.1472-765X.2005.01778.x.

Kailasapathy, K. (2009). Encapsulation technologies for functional foods and nutraceutical product development. CAB Reviews: Perspectives in Agriculture, Veterinary Science, Nutrition and Natural Resources, 4(33). http://doi.org/10.1079/ PAVSNNR20094033.

Khanna, O., Moya, M. L., Opara, E. C., \& Brey, E. M. (2010). Synthesis of multilayered alginate microcapsules for the sustained release of fibroblast growth factor- 1 . Journal of Biomedical Materials Research. Part A, 95(2), 632-640. http://doi.org/ 10.1002/jbm.a.32883.

Klein, J., Stock, J., \& Vorlop, K. (1983). Microbiology and biotechnology pore size and properties of spherical Ca-Alginate biocatalysts (pp. 86-91).

Klokk, T. I., \& Melvik, J. E. (2002). Controlling the size of alginate gel beads by use f high electrostatic potential. Journal Microencapsulation, 19(4), 415-424.

Kobašlija, M., \& McQuade, T. (2006). Removable colored coatings based on calcium alginate hydrogels. Biomacromolecules, 7(8), 2357-2361. http://doi.org/10.1021/ bm060341q.

Krasaekoopt, W., Bhandari, B., \& Deeth, H. (2004). The influence of coating materials on some properties of alginate beads and survivability of microencapsulated probiotic bacteria. International Dairy Journal, 14(8), 737-743. http://doi.org/10. 1016/j.idairyj.2004.01.004.

Kusuktham, B., Prasertgul, J., \& Srinun, P. (2014). Morphology and property of calcium silicate encapsulated with alginate beads. Silicon, 6(3), 191-197. http://doi. org/10.1007/s12633-013-9173-z.

Lee, J. S., Cha, D. S., \& Park, H. J. (2004). Survival of freeze-dried Lactobacillus bulgaricus KFRI 673 in chitosan-coated calcium alginate microparticles. Journal of Agricultural and Food Chemistry, 52, 7300-7305. http://doi.org/10.1021/ jf040235k.

Lee, K. Y., \& Heo, T. R. (2000). Survival of Bifidobacterium longum immobilized in calcium alginate beads in simulated gastric juices and bile salt solution. Applied and Environmental Microbiology, 66(2), 869-873. http://doi.org/10.1128/AEM. 66.2.869-873.2000.

Leung, A., Nielsen, L. K., Trau, M., \& Timmins, N. E. (2010). Tissue transplantation by stealth-coherent alginate microcapsules for immunoisolation. Biochemical Engineering Journal, 48(3), 337-347. http://doi.org/10.1016/j.bej.2009.10.007.

Liserre, A. M., Ré, M. I., \& Franco, B. D. G. M. (2007). Microencapsulation of bifidobacterium animalis subsp. Lactis in modified alginate-chitosan beads and evaluation of survival in simulated gastrointestinal conditions. Food Biotechnology, 21(May 2013), 1-16. http://doi.org/10.1080/08905430701191064.

Mandal, S., Puniya, a. K., \& Singh, K. (2006). Effect of alginate concentrations on survival of microencapsulated Lactobacillus casei NCDC-298. International Dairy Journal, 16, 1190-1195, http://doi.org/10.1016/j.idairyj.2005.10.005.

Martoni, C., Bhathena, J., Jones, M. L., Urbanska, A. M., Chen, H., \& Prakash, S. (2007). Investigation of microencapsulated BSH active lactobacillus in the simulated human GI tract. Journal of Biomedicine \& Biotechnology, 2007(7), 13684. http:// doi.org/10.1155/2007/13684

Mihara, Y., Sikder, M. T., Yamagishi, H., Sasaki, T., Kurasaki, M., Itoh, S., et al. (2016). Adsorption kinetic model of alginate gel beads synthesized micro particleprussian blue to remove cesium ions from water. Journal of Water Process Engineering, 10, 9-19. http://doi.org/10.1016/j.jwpe.2016.01.001.

Minekus, M., Alminger, M., Alvito, P., Ballance, S., Bohn, T., Bourlieu, C.,... Brodkorb, A. (2014). A standardised static in vitro digestion method suitable for food - an international consensus. Food \& Function, 5(6), 1113-1124. http://doi.org/10.1039/c3fo60702j.

Muthukumarasamy, P., Allan-wojtas, P., \& Holley, R. (2006). Stability of lactobacillus reuteri in different types of microcapsules. Food Microbiology and Safety, 71(1), 20-24.

Prakash, S., Tomaro-Duchesneau, C., Saha, S., \& Cantor, A. (2011). The gut microbiota and human health with an emphasis on the use of microencapsulated bacterial cells. Journal of Biomedicine and Biotechnology, 2011. http://doi.org/10.1155/2011/ 981214.

Quong, D., Neufeld, R. J., Skjåk-Braek, G., \& Poncelet, D. (1998). External versus internal source of calcium during the gelation of alginate beads for DNA encapsulation. Biotechnology and Bioengineering, 57(4), 438-446. Retrieved from http://www.ncbi.nlm.nih.gov/pubmed/10099220.

Santos, C. J. E., Wei, T. S., Cho, B., \& Kriven, W. M. (2013). A forming technique to produce spherical ceramic beads using sodium alginate as a precursor binder phase. Journal of the American Ceramic Society, 96(11), 3379-3388. http://doi org/10.1111/jace.12584.

Sarmento, B., Ribeiro, a. J., Veiga, F., Ferreira, D. C., \& Neufeld, R. J. (2007). Insulinloaded nanoparticles are prepared by alginate ionotropic pre-gelation followed by chitosan polyelectrolyte complexation. Journal of Nanoscience and Natechnology, 7(8), 2833-2841. http://doi.org/10.1166/jnn.2007.609.

Sartori, C., Finch, D. S., Ralph, B., \& Gilding, K. (1997). Determination of the cation content of alginate thin films by FTi.r. spectroscopy. Polymer, 38(1), 43-51. http://doi.org/10.1016/S0032-3861(96)00458-2.

Shi, J., Alves, N. M., \& Mano, J. F. (2007). Chitosan coated alginate beads containing poly(N-isopropylacrylamide) for dual-stimuli-responsive drug release. Journa of Biomedical Materials Research. Part B, Applied Biomaterials, 83(2), 340-344. http://doi.org/10.1002/jbmb.

Singh, V., \& Preeti. (2015). Mesoporous titania spheres derived from sodium alginate-gum acacia composite beads: Efficient adsorbent for "Reactive blue H5G" dye. Journal of Environmental Chemical Engineering, 3(4), 2727-2737. http://doi.org/10.1016/j.jece.2015.09.021.

Smidsrd, O., \& Skjak-Brae, G. (1990). Alginate as immobilization matrix for cells Tibtech, 8(March), 71-78.

Sohail, A., Turner, M. S., Coombes, A., Bostrom, T., \& Bhandari, B. (2011). Survivability of probiotics encapsulated in alginate gel microbeads using a novel impinging aerosols method. International Journal of Food Microbiology, 145(1), 162-168. http://doi.org/10.1016/j.ijfoodmicro.2010.12.007.

Sullivan, A., \& Nord, C. E. (2005). Probiotics and gastrointestinal diseases. Journal of Internal Medicine, 257(1), 78-92. http://doi.org/10.1111/j.1365-2796.2004 01410.x.

Tam, S. K., Bilodeau, S., Dusseault, J., Langlois, G., Hallé, J.-P., \& Yahia, L. H. (2011). Biocompatibility and physicochemical characteristics of alginate-polycation microcapsules. Acta Biomaterialia, 7(4), 1683-1692. http://doi.org/10.1016/j. actbio.2010.12.006.

Tam, S. K., Dusseault, J., Polizu, S., Ménard, M., Hallé, J. P., \& Yahia, L. (2005) Physicochemical model of alginate-poly-l-lysine microcapsules defined at the micrometric/nanometric scale using ATR-FTIR, XPS, and ToF-SIMS. Biomaterials, 26, 6950-6961. http://doi.org/10.1016/j.biomaterials.2005.05.007.

Tanaka, H., \& Matsumura, M. (1983). Diffusion characteristics of substrates in CaAlginate gel beads.

Thu, B., Bruheim, P., Espevik, T., \& Skj, G. (1996). Alginate polycation microcapsules I. Interaction between alginate and polycation. Biomaterials, 17(10), 1031-1040.

Thu, B., Bruheim, P., Espevik, T., Smidsrød, O., Soon-Shiong, P., \& Skjåk-Braek, G. (1996). Alginate polycation microcapsules. II. Some functional properties. Biomaterials, 17(11), 1069-1079. Retrieved from http://www.ncbi.nlm.nih.gov/ pubmed/8718966.

Tripathi, M. K., \& Giri, S. K. (2014). Probiotic functional foods: Survival of probiotics during processing and storage. Journal of Functional Foods, 9(1), 225-241. http://doi.org/10.1016/j.jff.2014.04.030.

Zhang, Z., Zhang, R., \& McClements, D. J. (2016). Encapsulation of ??-carotene in alginate-based hydrogel beads: Impact on physicochemical stability and bioaccessibility. Food Hydrocolloids, 61, 1-10. http://doi.org/10.1016/j.foodhyd.2016. 04.036. 